OMEGA, Vol. 69(3) 283-304, 2014

\title{
DEATH ON THE DIGITAL LANDSCAPE: A PRELIMINARY INVESTIGATION INTO THE GRIEF PROCESS AND MOTIVATIONS BEHIND PARTICIPATION IN THE ONLINE MEMORIAM
}

MICHAEL J. EGNOTO, PH.D. Student

JOSEPH M. SIRIANNI, PH.D. Student

CHRISTOPHER R. ORTEGA, PH.D. Student

MICHAEL STEFANONE, PH.D.

University at Buffalo

\begin{abstract}
Increasingly, individuals are bonding and maintaining relationships online. These digital representations of ourselves allow us to connect with others in ways previously not possible. One behavior that is growing in online presentations of self is grieving after the death of an individual in our social network. This work investigates the outcomes of online grieving from a transcorporeal communication model perspective, and draws conclusions on the outcomes of online grief behaviors.
\end{abstract}

All humans face loss and death. We face the loss of friends, family, partners, co-workers, and, eventually, we face our own transition from living to dead. In general, we hope that the transition away from life is after years of meaningful relationships and good living - however, this is not always the case. In the United States, roughly 50 out of 100,000 teens die every year. In other words, the death rate of teens can be represented as 1 out of 2,000 adolescents in the United States,

(C) 2014, Baywood Publishing Co., Inc. doi: http://dx.doi.org/10.2190/OM.69.3.d http://baywood.com 
or are slightly better than drawing a straight flush in a game of poker. Half of those deaths come from unintentional injuries, with the majority of the remaining deaths being comprised of suicides, homicides, and health complications (CDC.gov, retrieved August 2, 2012). Social networking site usage is becoming progressively more pervasive in our society, and is especially crucial for maintaining relationships among younger persons. Considering the frequency of these deaths and accounting for the popularity of social networking uncovers an interesting phenomenon. What happens to our digital persona when we die? Over 30 million dead people have profiles on the SNS Facebook (Technorati.com, retrieved Oct. 2, 2012); and the practice of posting on the SNS page of the deceased is not an uncommon one. The online communities people are participating in are now starting to grieve in ways that mimic our offline practices.

An increasing amount of online communities are hosting remembrances for individuals who have died (Arthur, 2009; DeGroot, 2012; Nager \& De Vries, 2004). Brubaker and Hayes (2011) found online memorialization melds existing post-mortem practices and communication with new technologies to share memories, post updates, and maintain connections with the deceased. Lester (2012) investigated the different uses of language associated with loss in online environments, and DeGroot (2012) found that online outlets like social networking sites are good for maintaining relational continuity with deceased personsfinding that people utilize these online services to make sense of the loss, and to continue or uphold the relationships with the departed.

After the death of an individual, the deceased's page becomes an avenue for the emotional outpourings of people visiting the page, creating alerts that travel outward in their own networks creating awareness to other more emotionally distant relations (friends of friends). In other words, as more people find out about the death and make note of it through commenting or some other SNS avenue, other people are notified of that death because of the activities of the living. Detmer and Lamberti (1991) stated that increasing emotional distance was a coping mechanism that worked for grief and conflict. Thus, for people who start with more emotional distance who have less relational intensity with the deceased, the need to express grief and the intensity of that grief experienced by those people is also lessened. At what point is the emotional distance so great that we no longer express sympathy about the deceased? Recently, scholarly literature has begun to analyze grief online (Arthur, 2009; DeGroot, 2009b; DeGroot, 2012; Hess, 2007; Nager \& De Vries, 2004; Roberts, 2004). However, the types of people who participate in such mourning behavior and the extent to which such behavior occurs, remains unclear.

Transcorporeal communication ( $\mathrm{TcC}$ ) is a useful framework to help understand the difference between the biological and social death of individuals (DeGroot, 2009a). DeGroot's (2009a) conceptualization of TcC suggests bonds with deceased persons do not need to be severed entirely, but rather are transformed so the living can grow and recover from the death of a loved one. Furthermore, TcC suggests that elements of an individual, like parts of their personality, sense of 
humor, and even the stories of their life (referred to as the agency of the individual), are partially stored in the surrounding social network of the bereaved (DeGroot, 2009b). Consequently, it can be posited that the digital archive of such information creates representations of the deceased that could exist indefinitely. Thus, this article seeks to begin an investigation into the motivations surrounding participation in online memorials.

The current research reports on the results of surveying traditional and digital mourners. We leverage the $\mathrm{TcC}$ framework to guide this investigation and our understanding of the scope, as well as the antecedents and consequences of this behavior. In addition, we investigate the perceptions of individual's self and of others with regard to digital mourning as a coping strategy. This work begins testing the elements of the TcC model (DeGroot, 2009a) in a quantitative fashion.

We discuss relevant literature on grief, relationships, and online mourning to construct our argument. We finally posit a refinement to $\mathrm{TcC}$ for use with digital mourning. The purpose of this work is to begin a general exploration into the extent of the online population that is engaging in this behavior or is at least aware of it; whether the perceptions of online grieving are consistent between users and non-users, and how individuals actually engage in online grieving. Holistically, this work seeks to understand if grieving by individuals is moving toward digital formats and under what circumstances. Moreover, if a trend toward online grieving is occurring, we seek to determine if this is a benefit for people creating a healthier grief environment. To proceed in this work, we operate under the following assumptions: grief is a natural extension of life, and focuses on coping with the loss of an individual from two primary perspectives; that people must learn to adjust to life without the person; and that individuals have to deal with the associated stresses of their loss with others in their social network.

Interpersonal relationships offer significant contributions to our well-being. Moreover, we believe a variety of relationship types are necessary to guard an individual from the negative consequences of isolation. This is problematic, however, and relationship maintenance can be hard - especially when environmental factors like distance come into play. We believe that online technology like social networking sites (SNS) can mitigate the factors that make communication over distance difficult.

SNS are pervasive and beneficial to relationship creation and perpetuation. Maintaining relationships has associated costs in cognitive and temporal resources. Online communication, however, offers benefits in certain types of interactions that we find difficult to address in person, like awkward requests or instances where a person feels vulnerable emotionally or physically for having a real-life presence.

\section{LITERATURE REVIEW}

To address the impact of online grieving, grief literature must first be addressed in offline contexts. Without an understanding of how the bereaved act, drawing 
conclusions from grief in different media would be premature at best. Relevant to understanding how we grieve is the impact of relationships, as we have mentioned relational closeness likely impacts how grieving affects individuals after a loss. The nature of how people interact with one another plays a huge impact on how we grieve. It is not difficult to call to mind the comparison of losing a friend or loved one and comparing that body of emotion to the one experienced by the loss of an acquaintance or co-worker. The nature of the relationship, its duration, and its intensity all factor into the gravity of the loss of the individual after they die. Only after grief and relationships are discussed, can be begin to understand social networking research to see how computer-mediated communication and SNS influence the grief process.

\section{Grief}

Grief is the sense of loss and emotional turmoil we experience after the death of an individual in our social network. Grief is a pervasive emotion that is ingrained in the human condition, and is a typical response to loss. Grief is complex-an emotion that is far more intricate than an off/on switch, and has interested scholars for years. A particularly difficult facet of studying grief is modeling the experience appropriately for a wide range of individuals. Scholars need to understand the different stages of grieving and the yearning/emotional needs of the bereaved individual throughout the healing process.

Sanderson and Cheong (2010) describe grief as a normal reaction to the death of a family member or friend, with grief being one of the most trying human experiences in life (Bosticco \& Thompson, 2005). Stroebe and Schut (1999) suggest the most important part of grieving is confronting the reality of the death, and adjusting to life without the person. Of secondary concern is the mitigation and addressing of the associated stresses with the loss of a known individual. These stresses can manifest in a number of ways, but a common manifestation is the yearning for things to return to how they were with the individual. Maciewjewski, Zhang, Block, and Prigerson's (2007) work found that yearning has some of the longest and strongest effects over the course of the study and were superseded only by acceptance of the loss. Yearning is characterized by a strong desire for some continued connection or experience with the deceased. Prolonged yearning is associated with negative behavior that can lead to medical intervention (Maciewjewski et al., 2007); however not all behaviors which facilitate relationship maintenance with the departed develop into unhealthy manifestations. Further, some form of continued connection with the deceased is often beneficial to the bereaved (Klass, Silverman, \& Nickman, 1996).

TcC (DeGroot, 2009a) posits that death does not force the termination of interpersonal relationships. Research has investigated the processes through which relationships with deceased are maintained (DeGroot, 2009a; Glick, Weiss, \& Parkes, 1974; Mitchell, 2007). Results suggest that despite struggles associated 
with maintaining these kinds of relationships, they contribute to survivors' sense of self (Hallam et al., 1999; DeGroot, 2009a). DeGroot (2009a) found that individuals often write to the deceased as part of the grieving process in a manner that mimicked interpersonal exchange. These exchanges were characterized as ways of maintaining relational continuity post mortem (Gilbertson, Dindia, \& Allen, 1998; Sigman, 1991). (See Figure 1.)

As conceptualized by TcC (DeGroot, 2009a), the exchange between the bereaved and the deceased mimics traditional interpersonal exchanges with several modifications. First, communication occurs entirely within the bereaved individual. In essence, exchange occurs only between the bereaved and their cognitive manifestation of the deceased. As this communication is intrapersonal, the opportunity for outside influence is heavily restricted. Thus, the feedback that is received via the manifestation of the deceased is low in ambiguity and easily interpreted by the bereaved, giving a direct line of communication within the individual between their conscious self and their manifestation of the deceased.

Second, the avenue for feedback is not as easily defined within a TcC paradigm as it is between individuals in interpersonal interactions due to the lack of a physical manifestation of the deceased. In typical interpersonal exchanges, feedback can be differentiated in a variety of ways. First, feedback can be conceptualized as a dichotomous variable where it is either received or is not. Secondly, feedback can be conceptualized as verbal or non-verbal exchanges between parties. Simply gauging body language during an interpersonal exchange can be informative, even if no words accompany the action. Conversely, we receive affirmation and feedback without visual cues by the type of feedback the person gives us during a conversation. Finally, feedback can be measured in terms of outcomes. For example,

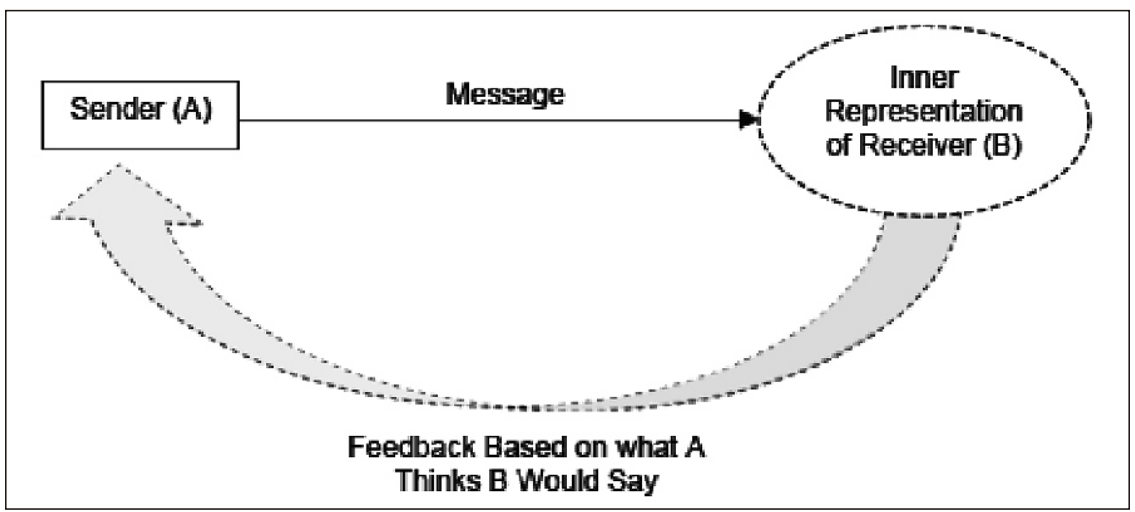

Figure 1. Hypothesized model of Transcorporeal Communication (TcC) (Developed by Jocelyn M. DeGroot). Note: All communication in the proposed TcC model (Degroot, 2009a) occur within a single communicator. 
an exchange could include a request and the feedback could be interpreted in terms of the (non)fulfillment of that task.

Computer-mediated communication (CMC) allows editing of asynchronous messages and results in higher levels of perceived immediacy and affection (Walther, 2007). Interpersonal communication via CMC is also associated with idealization of communication partners. These processes are a function of hyperpersonal communication (Walther, 2007). Thus, it is likely that even though the deceased are unable to communicate, the bereaved may turn to a communication medium that allows for high levels of immediacy, affection, and idealization of the departed. Couple those interpersonal communication benefits with the additional social support that can be accessed through CMC (Walther \& Boyd, 2002), the investigation of $\mathrm{TcC}$ in digital environments is highly salient to grief-related scholarship.

\section{Relationships}

Humans are social creatures who crave companionship. The desire for interactions with others goes beyond shared resources, as we all confide emotionally and psychologically in our partners, friends, and family members. These close ties are often relied upon during difficult times throughout an individual's life. However, social networks are not entirely comprised of close, intimate ties. Additional relationships in the form of weak ties, or acquaintances, represent a large portion of a person's social network. Both types of relationships (close intimate ties and distant weaker ties) seem to contribute to overall health, but come at very different personal costs.

Social support and positive social interactions are associated with positive health outcomes (Cohen, 2004). Buffering hypothesis (Arson, Wilson, \& Akert, 2007) suggest that social support protects us against the damaging effects of stress. Therefore, simply having relationships may contribute to well-being.

Maintaining a few close relationships is beneficial, but maintaining weak-ties offers benefits in much the same way that maintaining strong-ties do (House, Landis, \& Umberson, 1988). Research shows that social isolation is a major contributing factor that leads to death (Friedmann, Thomas, Liu, Morton, Chapa, \& Gottlieb, 2006). Social isolation is related to depression and mortality regardless of demographics and the quality of medical care a person receives (Friedmann et al., 2006). The physical and psychological impact of strong- and weak-tie relationships cannot be over emphasized from a health perspective. Therefore, one must maintain a variety of relationships for a healthy life.

Despite the benefits gained from maintaining diverse relationships, keeping connections with others can be difficult. Physical distance can challenge relationships (Maguire \& Kinney, 2010). Time zones, travel, language, borders, and weather all create additional costs to maintaining relationships over distance. All of these factors complicate relationships because of increases in the difficulty of 
having regular communication. For example, to try to minimize the difficulties of large distance communication, the Moscow-Washington hotline was developed to let the leaders of the United States and Russia communicate directly to reduce the risk of nuclear disaster.

Healthy relationships are associated with high communication frequency (Huebner \& Howell, 2003) and technology can lower the cost of maintaining relationships and create avenues for more regular interactions (Johnson, Haigh, Becker, Craig, \& Wigley, 2008). For example, SNS allows users to post status updates and share photographs, which facilitate regular online conversations. Therefore, individuals who utilize $\mathrm{CMC}$ to maintain diverse networks of relationships receive benefits associated with robust social networks while lowering the costs of maintaining those relationships.

\section{Online Social Networks}

Online social networking sites are pervasive among young Americans, and these networks pull together relationships of all types. People maintain close and distant ties online, and manage their self-presentation in these digital environments. Interestingly, because online relationships can be maintained at such a low cost (in terms of time and effort) people are placed in a situation where grieving before was not an option. Prior to online mourning, the amount of relationships a person had that they would grieve for was comparatively small. It is simply too difficult to keep in touch with hundreds or thousands of people without an online environment like a SNS. These online environments are developing their own norms and mores of acceptable behavior, and the personal characteristics individuals display on these environments conform to these self-prescribed norms.

The popularity of SNS represents one of the fastest adoptions of a communication technology since the web was developed in the early 1990s. Academic research on SNS is growing, with focus on a range of issues including privacy (Gross, Acquisti, \& Heinz, 2005), identity and reputation (Walther, Van Der Heide, Kim, Westerman, \& Tong, 2008), and the role these sites play in relationship maintenance and the development resources like social capital (Choi, 2006). These sites enable individuals to connect their personal profile to the profiles of other users, resulting in a public display of one's entire social network. On a technical level, becoming a "friend" requires only a few clicks of the mouse, rather than any investment in conversation or social support. This results in a diversity of approaches to understanding SNS "friendship."

In network terms, the most frequently measured aspect of relationships is tie strength, or intensity, an indication of how close a respondent reports being to each network member (McCarty, 1996). Strong tie contacts are characterized by frequent, reciprocal communication and usually a long, stable history of interaction. Often, strong ties constitute relationships with family and close friends. In contrast, weak ties are characterized by infrequent communication, low reciprocity, 
and a lack of emotional closeness (Granovetter, 1973, 1982). Some individuals may have large networks comprised of numerous weak-tie contacts, while others may have small networks comprised of a few strong ties. Weak and strong tie proportions in ego networks are often a function of the time necessary to maintain those relationships. Strong tie relationships are more costly to maintain given their richness and intensity. This is one of the reasons why internet-based communication tools have become so popular (Stefanone \& Jang, 2007).

Some communication is actually better suited to CMC environments due to the ability to carefully craft messages (Collins Tidwell, \& Walther, 2006). This message crafting is well suited to weaker relationships like acquaintances which have lower emotional intensity between parties. Recall hyperpersonal communication allows editing of self-presentation to create an idealized self. The ability to modify one's image people allows for strategy and planning; creating digital avatars superior to the traits of the people represented. Conceptualizing the differences in online relationships is important when modifying self-presentation. Hyperpersonal communication allows for an idealization of a person's best traits, but also creates a risk where individuals with offline information would be able to uncover the exaggerations. Therefore, hypersonal communication is best suited to weaker ties that do not have developed relationships that expose these inconsistencies between the virtual and actual self. We call these varying levels of intensity between people relational closeness.

The factors that contribute to relational closeness (McCarty, 1996) are not fixed. Some of the weakest SNS relationships result from promiscuous friending where users friend people they have never met face-to-face (Rosen, Stefanone, \& Lackaff, 2010). Other relationships occur because people are forced to interact with one another (Granovetter, 1982). This voluntariness of interactions could influence a person's behaviors (Haferkamp, 1991). It is easy to imagine a scenario where individuals are forced to interact with others, like professional work groups which result in mandatory relationships. Mandatory associations could have an effect on interpersonal attraction and must be accounted for. These mandated relationships are related to a sense of imbalance, where one person feels exploited and tries to distance themselves from the offender as much as possible (Hess, 2000).

In the current study, we propose that relationship balance links voluntariness and closeness of relationships (Laursen \& Bukowski, 1997). Relationship balance is the sense of fairness that partners perceive regarding their relationships; and research shows relationship balance contributes to both liking and behavioral outcomes (Claes, Hurley, \& Stefanone, 2012). Balance then is the internal gauge of equity in a relationship; but what if a SNS relationship comes to a sudden and abrupt change? In the case of a death, any imbalance that existed becomes much more complicated, and the means of resolving that imbalance also becomes more difficult.

$\mathrm{TcC}$ was conceptualized with digital environments in mind, and has already been applied to SNS (DeGroot, 2009b). Recently, Falconer et al. (2011) refer to SNS in grieving contexts as informal online memorials which allow for faster 
communication, normalizing of the death experience, the ability to share emotions more freely, a broader and more durable community, and a safe and accessible place for people to grieve. Those tools for a durable community (varied relationships) as well as quick and free transmission of information are key factors of low-cost healthy relationship maintenance with good psychological and physical health outcomes. However appropriate $\mathrm{TcC}$ is to this investigation, additional factors need to be considered.

A key focus of the current research is to better understand the characteristics of (non)digital mourners. In addition, we seek to understand their self-reported justifications for participation in online grieving, the frequency of online grieving, the manner in which grief is communicated online (publicly or privately), as well as to determine if the frequency of online usage contributes to the type or intensity of any grief behaviors online. Finally, we seek to understand if the perceptions of acceptability or normalcy of online behavior, as well as personal religious belief structures influence any of the above facets of online grieving.

Given the literature outlined above regarding interpersonal relationships and technology use, the goal of the current study is to address a series of broad research questions. These include questions about:

RQ1: What is the extent of the population that is aware of online grieving, and do they participate in it?

RQ2: Do people think online grieving is appropriate - and to what extent do they feel it is either appropriate or not?

RQ3: How do people actually grieve online (posts, videos, pictures, etc.)?

Social identity theory is used to guide the inquiry into these questions as it has been used as a CMC framework in the past (Stromer-Galley \& Martey, 2009).

Social identity theory (Tajfel \& Turner, 1986) grew from the notion that selfidentity is derived from one's personal perceptions social group. Therefore, the perceptions of self and the perceptions of what others deem appropriate impact the desire to adopt new behaviors. In the context of the current research, these perceptions will likely influence the decision to engage in online grieving. Homophily (McPherson, Smith-Lovin, \& Cook, 2001) tells us that people who find a behavior acceptable will also tend to believe their social network will also find it acceptable. This will lead them to be more likely to adopt the behavior than an individual that lacks assurance from their group for some reason that impacts their sense of homophily.

People with non-reciprocal friendship networks (Aloise-Young, Graham, \& Hansen, 1994) and mixed gender pairs (Ibarra, 1992) are known to be outsiders or to receive group ostracism. Gender differences in communication are well documented in CMC (Tu, Yen, \& Blocher, 2011). These gender differences result in women having difficulty creating and maintaining their online presence $(\mathrm{Tu}$ et al., 2011). Marginalized groups (like women) attempt to overcome these 
difficulties through anonymity in online interactions (Christopherson, 2007). However, SNS usage eliminates the ability to be anonymous as a by-product of its primary purpose (connecting known people to each other). Thus, we propose the following hypothesis:

H1: Perceived normalcy of online grieving has a positive relationship with online grieving behavior.

Women are also known to manage information more closely in SNS environments than men (Rui \& Stefanone, 2012). Therefore, women are likely to be more concerned with perceptions of others before committing to a new behavior like online grieving as a way of minimizing the negative consequences they encounter in $\mathrm{CMC}$ interactions. Thus,

H1a: The effects of perceived normalcy are greater for females.

Recall that individual religious belief structures, or religiosity, likely has a relationship with online grieving. Sanderson and Cheong (2010) found a relationship between online grieving of celebrities and religious underpinnings as expressions of that grief. Religiosity has also been shown to combat feelings of exclusion and of being an outsider (Wesselmann \& Williams, 2010). Higher religiosity is linked to more online grieving, and a sense that others in your group are similar to you (homophily) and therefore also grieve online. We therefore expect higher levels of reported religiosity to have a positive relationship with the perceived normalcy of on- and offline grieving behavior. Thus,

H2: Religiosity has a positive relationship with perceived normalcy of online grieving.

Much of the extant grief literature focuses on high intensity relationships. SNS allow users to maintain relationships of varying intensity and research has shown that the benefit of SNS maintenance is from weaker connections in networks (Claes et al., 2012). This is due to the types of relationships people maintain, and the way they access those relationships. Close ties with high intensity do not use SNS as a means of communication regularly because they have access to other more expedient avenues of communication (phone calls, face to face visits, etc.). These communication channels may be prohibitive or awkward with weaker ties. Few people would feel comfortable calling all of their SNS friends in real life, let alone meeting them for coffee or drinks. It is awkward because we lack the tools for effective personalness in our communication. Without having the information necessary to make connections with individuals, people often feel anxious when they are suddenly thrust into conversation with no known common topics. Thus, much online grieving might follow a similar pattern, where close ties are grieved in more traditional means with greater personalness and weaker ties are grieved in these public settings where less personalness does not create apprehension. 
TcC (DeGroot, 2009a) suggests that elements of individuals' personalities are maintained in their social network after death. This personality imprinting lends itself well to online environments where large numbers of people can contribute bits of information (in this instance elements of the individual's personality) in order to help with the grieving process of the whole group. This also allows people to gain confirmation from a group as to the accuracy of their information, and gain additional social support. Thus,

H3: As relationship intensity increases, offline grieving will increase.

H3a: As relational intensity increases, personalness of grieving will increase.

\section{METHOD}

\section{Participants}

Data collection occurred via an online survey during the 2011-2012 academic year. The sample consisted of 270 undergraduate students who used SNS. The survey was constructed with the intention of capturing the relevant motivational and behavioral correlates of online grieving. As such, the survey contained instruments on self-based motivations regarding online posting behavior, other-based motivations, relationship intensity, sentiment toward posting behavior (or, normalcy), and a multi-faceted condolence giving measure. In addition, a number of spirituality and demographic questions were included. All procedures were approved by the institutional review board.

\section{Instrument Development}

Scales were developed from prior literature and tested for reliability. To understand the motivations for the self that lead to posting, a 4-item measure was constructed focusing on internal and external motivations for and acceptability of participation in digital memorialization. The scale showed acceptable intercorrelation between items, and was considered reliable $(\alpha=.85 ; \mathrm{KMO}=.787)$. The Motivations of Self measure construction was developed by the authors to encapsulate two motivational sources: internal causes, which develop from within the person, like "It gave me a sense of closure"; and external like "It let others know I cared about this person," which are derived from the environment the individual occupies, or forces applied on the individual from the remainder of their social network. Principal component analysis with varimax rotation, however, demonstrated that only one component existed within the measure, and thus an average unweighted score of the items was calculated for analysis purposes for all later analyses including the motivations of self-measure.

Motivations of others was constructed with the same items as motivations for self but with different wording for contextual agreement $(\alpha=.89 ; \mathrm{KMO}=.812)$. 
The Motivations of others measure construction was identical to the motivations of self measure, with the only exception being the syntactic construction of the items to refer to what a person thought the motivations of other individuals might be, instead of their own personal motivations. Principal component analysis with varimax rotation also demonstrated that a single component existed within this measure, and an average unweighted score of the items was calculated for analysis purposes for all later analyses like the motivations of self-measure.

The measure of normalcy was also scrutinized by principal component analysis with varimax rotation, yielding two principal components. The rotated component matrix, however, showed signs of heavy cross loading with two items, and thus they were discarded. The subsequent 4 -item measure yielded a single component which (like motivations of self/others) was recalculated into an average unweighted score for analysis purposes for the rest of the article.

The remaining 4-item measure $(\alpha=.88 ; \mathrm{KMO}=.817)$ was used for analysis purposes. Relationship strength $(\alpha=.98 ; \mathrm{KMO}=.692)$ was derived from Marsden and Campbell (1984) and has been used with good effect in online environments (Stefanone, Kwon, \& Lackaff, 2012). Condolence giving was divided into three categories: online condolence giving on the page of the deceased (comprised of four yes or no items relating to posting behavior); online condolence giving on the participants page (comprised of two yes or no items relating to posting behavior); and offline condolence giving (comprised of six yes or no items relating to off-line behaviors). The dichotomous nature of condolence giving prevented reliability construction per se, but post-hoc analyses and open-ended responses suggested that the options were fairly pervasive at capturing the behaviors of the participants. Religiosity is measured with a 5-item measure (Koenig, Meador, \& Parkerson, $1997 ; \alpha=.69$ ) which assesses religious beliefs on a variety of dimensions.

\section{RESULTS}

\section{Frequency Analysis}

Research question 1 asked to what extent people are aware of online grieving, and do they participate in it. Therefore, a frequency analysis of 270 undergraduate students from a large northeastern university who use SNS (age, $M=19.91$, $S D=1.45 ; 44.4 \%$ male, $49.5 \%$ female, $6.1 \%$ no response; $57.8 \%$ White, $5.5 \%$ Black, $16.7 \%$ Asian, $20 \%$ Other/No Response) was conducted. Analysis showed that $54.4 \%$ of all respondents did have a deceased person in their online social network. Furthermore, $73.3 \%$ of all respondents reported a personal religious belief (52.7\% Christian, 2.5\% Muslim, 13.3\% Jewish, 4.8\% Eastern religions) that fit in with prominent religious paradigms, with $11 \%$ considering themselves as atheist or agnostic, and the remainder preferring not to identify their spirituality. Interestingly, $50.2 \%$ of the entire sample reported visiting the SNS page of a 
deceased person after finding out about their death, which equates to $93.88 \%$ of all participants who reported having a deceased person in their SNS.

Moreover, $25.8 \%$ of the entire sample (49.7\% of the sub-group with a deceased person in their SNS) reported some type of SNS grieving behavior after the death was discovered. Finally, the authors sought to investigate the average relational intensity of the deceased person most people experience in a SNS of university undergraduates. Analysis showed that only $8.8 \%$ of participants who had experienced a death, experienced a death of a best friend or family member and grieved in some way via SNS ( $N=147$, total 13$)$. Moderately close ties, casual friends, and persons with whom an individual has not had contact with in the last 12 months made up $23.8 \%$ (total 35 persons) of the total number of bereaved, with the remaining $67.3 \%$ (total 99 persons) being acquaintances and persons of low relational intensity. (See Table 1.)

\section{Inferential Analysis}

To address research question 2, which looked at whether or not people perceived online grieving as a socially appropriate act, the sample was divided into persons who had a death in their SNS and those who did not. An ANOVA of perceptions of the acceptability of others' posting motivations, $F(2,254)=11.824$, $p=.001$, as well as the suitability of normalcy, coping strategies, and acceptability, $F(2,259)=9.996, p=.002$, yielded significant results whereby those participants who experiencing a death in an individuals' network made them more accepting of the online grieving behavior of others (Death in network, $M=5.43, S D=1.23$; No death in network, $M=4.91, S D=1.19)$ and significantly more comfortable with online grieving normalcy (Death in network, $M=4.10, S D=1.12$; No death in network, $M=3.66, S D=1.12$ ).

To address research question 3 concerning how individuals actually grieved online, the types of grieving in SNS and the length of time those participants reported partaking in those behaviors were also of interest. A test of repeated measures was conducted that showed a significant difference, $F(2,133)=1477.47$, $p<.001$, whereby participants preferred to share information about the deceased $(M=4.74, S D=1.64)$ in online environments (in the form of general information about the individual or events held in their honor) in order to demonstrate that they cared about the individual $(M=4.71, S D=1.64)$ as opposed to simply gaining a sense of closure $(M=4.24, S D=1.63)$. A total of 89 participants posted for 1 week or less (33.7\%) with 54\% posting for 3 months or less to the account of the deceased. An additional $30 \%$ of individuals posted for between 3 and 12 months. The remaining $16 \%$ posted for one or more accounts of the departed. (See Table 2.)

\section{Hypothesis Testing}

To test H1-which looked at the relationship between perceived normalcy of online grieving and online grieving — a binary logistic regression referred to as 
Table 1. Descriptive Statistics and Zero-order Correlations for Variables; Means (Standard Deviations) along the Diagonal

\begin{tabular}{|c|c|c|c|c|c|c|c|c|c|c|}
\hline & Age & Gender & $\begin{array}{l}\text { Time on } \\
\text { SNS Daily } \\
\text { (min) }\end{array}$ & $\begin{array}{l}\text { Death in } \\
\text { SNS }\end{array}$ & $\begin{array}{l}\text { Offline } \\
\text { Grieving }\end{array}$ & $\begin{array}{l}\text { Online } \\
\text { Grieving }\end{array}$ & $\begin{array}{l}\text { Normalcy } \\
\text { (Self) }\end{array}$ & $\begin{array}{l}\text { Normalcy } \\
\text { (Other) }\end{array}$ & $\begin{array}{l}\text { Relationship } \\
\text { Intensity }\end{array}$ & $\begin{array}{l}\text { Religious } \\
\text { Activities }\end{array}$ \\
\hline Age & $\begin{array}{l}19.91 \\
(1.45)\end{array}$ & $-.14^{\star}$ & -.11 & -.02 & .03 & .12 & .03 & -.01 & .01 & -.11 \\
\hline Gender & & - & .05 & -.07 & .01 & -.03 & .10 & $.22^{\star *}$ & -.01 & .1 \\
\hline $\begin{array}{l}\text { Time on SNS } \\
\text { daily }\end{array}$ & & & $\begin{array}{l}101.75 \\
(77.62)\end{array}$ & .05 & .03 & .05 & .01 & .05 & .02 & -.04 \\
\hline Death in SNS & & & & - & .09 & .17 & $-.24^{\star \star}$ & $-.20^{\star \star}$ & .00 & -.03 \\
\hline $\begin{array}{l}\text { Offline } \\
\text { Grieving }\end{array}$ & & & & & $2.63(1.43)$ & $-.394^{\star \star}$ & .05 & .10 & $.306^{\star *}$ & .147 \\
\hline $\begin{array}{l}\text { Online } \\
\text { Grieving }\end{array}$ & & & & & & $1.49(.77)$ & .15 & .05 & .15 & -.02 \\
\hline $\begin{array}{l}\text { Normalcy } \\
\text { (Self) }\end{array}$ & & & & & & & $4.17(1.48)$ & $.477^{\star \star}$ & .03 & .12 \\
\hline $\begin{array}{l}\text { Normalcy } \\
\text { (Other) }\end{array}$ & & & & & & & & $5.22(1.24)$ & .02 & .05 \\
\hline $\begin{array}{l}\text { Relationship } \\
\text { Intensity }\end{array}$ & & & & & & & & & $4.19(1.08)$ & .16 \\
\hline $\begin{array}{l}\text { Religious } \\
\text { Activities }\end{array}$ & & & & & & & & & & $2.74(1.80)$ \\
\hline
\end{tabular}

Note: ${ }^{*}$ correlation is significant at the .05 level; ${ }^{* *}$ correlation is significant at the .01 level. 
Table 2. Linear and Binary Logistic Regressions of Normalcy (Self, Other) and Online Grieving

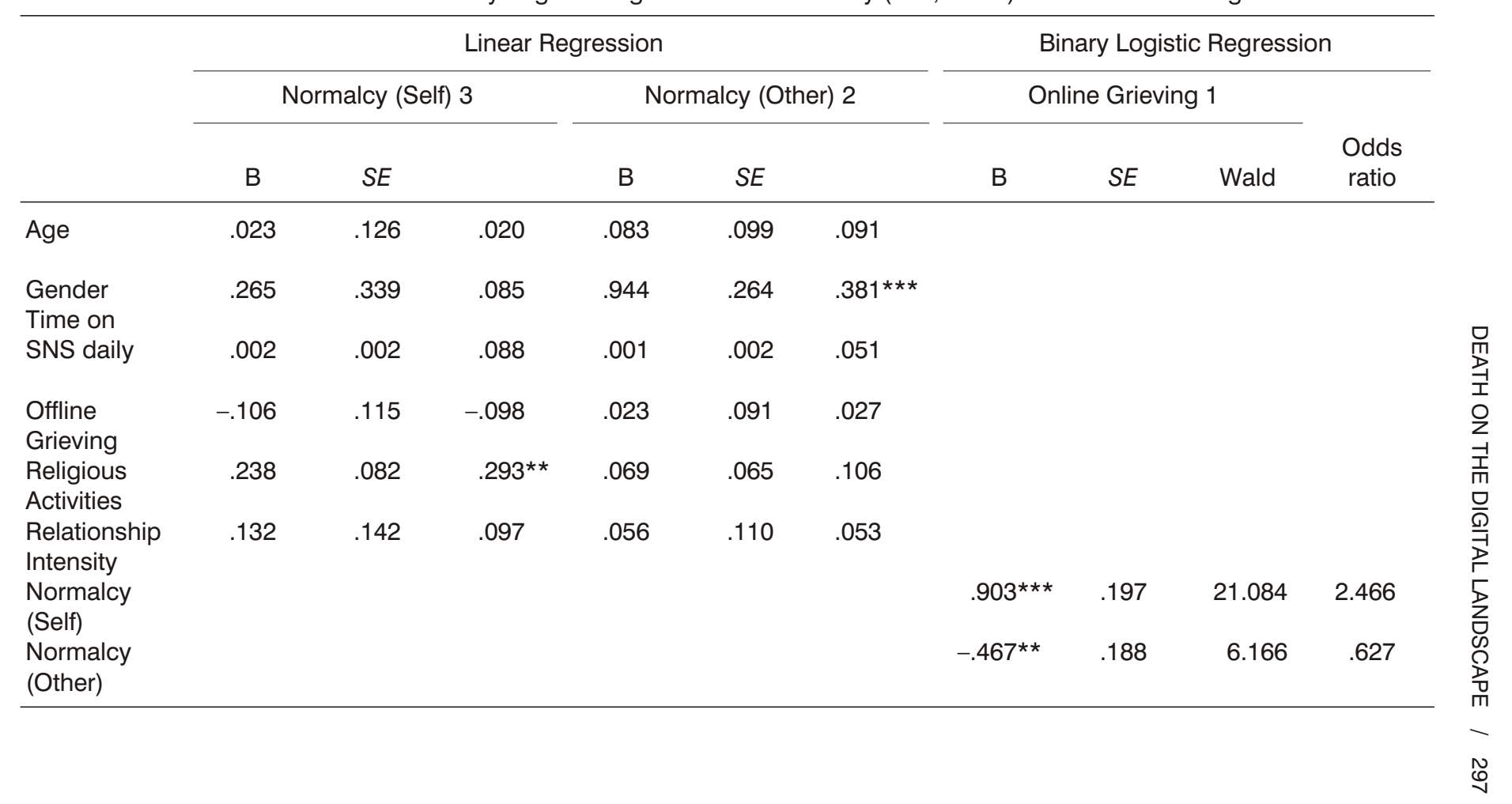


model $1, \chi^{2}(2, N=135)=31.325, p<.001$, was conducted to see if the perceptions of normalcy from the self and other predicted online grieving. The resulting model yielded a Nagelkerke $R^{2}$ of .276, indicating an adequate model fit and supporting H1. To investigate H1a, linear regression was conducted referred to as model 2, $p=.01, F_{150}=2.921$, adjusted $R^{2}=.109$, which shoed a strong, positive relationship whereby gender (specifically women) were influenced by the perceptions of normalcy of online grieving by others in their social network such that higher levels of acceptability as perceived in the network led to more online grieving.

Linear regression was conducted to investigate $\mathrm{H} 2$, which investigated religiosity, perceived normalcy of online grieving behavior, and online grieving. Results show that perceptions of normalcy for the self was predicted by religious activity such that as personal religious activity increased (i.e., engaging in prayer several times per week) the perception of the normalcy of online grieving also increased, $F(4,154)=2.18, p<.05$. This model explained about $6.8 \%$ of the variance, and supports $\mathrm{H} 2$.

Analysis for $\mathrm{H} 3$ - which stated that as relationship intensity increased, offline grieving would also increase-yielded a significant ANOVA whereby relationship intensity had a strong, positive relationship with offline grieving behaviors, $F(2,107)=2,681, p=.026$, such that as relational closeness increased (High closeness, $M=3.46, S D=1.45$; Low closeness, $M=2.17$, $S D=1.23$ ), so did involvement in offline condolence giving behavior, support for H3. H3a stated that as relational intensity increased, personalness of grieving would also increase. The effect was non-significant with online grieving behaviors and relationship intensity, but interestingly, trended in the opposite direction such that as emotional distance increased, so did online condolence giving behaviors, $p<.05$. H3a stated a positive relationship between relational intensity and personalness. An independent samples $T$-test was conducted to test this relationship; however, the relationship was not significant. H3 was not supported.

\section{DISCUSSION}

This work sought to explore the extent with which online grieving was occurring among a generalizable population and to begin to develop a profile of the persons who participate in this behavior, as well as understand the consensus of individuals who do not participate in online grieving. Furthermore, this work investigated the acceptability of utilizing SNS resources after experiencing a loss of a person in an individuals' network. Findings suggest that SNS grieving is not only happening, but is extremely common. Simply experiencing a death in a social network greatly (and significantly) influences perceptions about the acceptability of using online social networks in the grieving process - this suggests that given enough time and a broad enough network, individuals will almost universally find online grieving as a progressively more acceptable behavior. 
Facebook reports profiles have, on average, 120 connections with some student samples being exponentially higher (http://www.facebook.com/facebook/info, retrieved 7/6/12). As the population using SNS ages and more persons of varying demographics continue to join SNS of all kinds, the exposure to death faced by individuals using these digital services seeks to increase substantially. The low relational involvement (or weak relationship) of most SNS users to the deceased in our sample is a benefit, as it prevents them from utilizing online grief for coping, and instead more for information sharing about individuals. When considering the increase in offline grieving behaviors for closer relations with higher levels of involvement as compared to online behaviors with low relational involvement, one cannot help but suggest that online grieving is an emotion and time saving device. This device allows individuals to express all the expectations dictated by society for a death in their network, without exposing themselves to the physical intensity and commitments required with an offline behavior.

Grief scholarship needs to investigate the application of SNS as meaningful locations of discourse for grief-based communication, as this work uncovers the frequency at which these expressions are happening. People are experiencing loss, and coping with it through digital communities and their participation in that community is growing in acceptability and frequency as SNSs continue to become more pervasive in our lives. The simple fact of having death in SNS environments appears to be acting as a shibboleth for true acceptance in online grieving, creating a situation where experience grants admittance into accepting the SNS as a meaningful area to express loss. This is further emphasized by the public nature of grief, where individuals are more concerned with showing emotion for the deceased as opposed to gaining closure for themselves. The way people maintain relationships is changing as quickly as the way they are adapting to and dealing with loss is changing, and scholars need to investigate these phenomena thoroughly.

This work represents a first step into better understanding online grieving so better resources for these digital grievers can be constructed. DeGroot (2009a) suggested that $\mathrm{TcC}$ existed entirely within the individual and the internal manifestation of the bereaved. The model is well suited to online environments, and SNS communication offers many benefits to grief process. As the TcC model is so well constructed for applications in SNS, it is logical to apply it in new forms of online grieving. Expanding $\mathrm{TcC}$ to accommodate collective grief behaviors whereby multiple individuals contribute, reinforce, and put forth responses to the relational maintenance occurring with the bereaved across a whole network of individuals is a logical addition (see Figure 2). By creating a multi-input model for $\mathrm{TcC}$, the individual is still able to meaningfully draw information from the network of the deceased, allowing the bereaved chances to not only grieve, but to share information with one another. Moreover, the digital representation of the deceased draws upon the knowledge of the entire network, allowing for a richer, more robust dialogue to develop to grant closure to participants, or simply to share emotions with the group. 


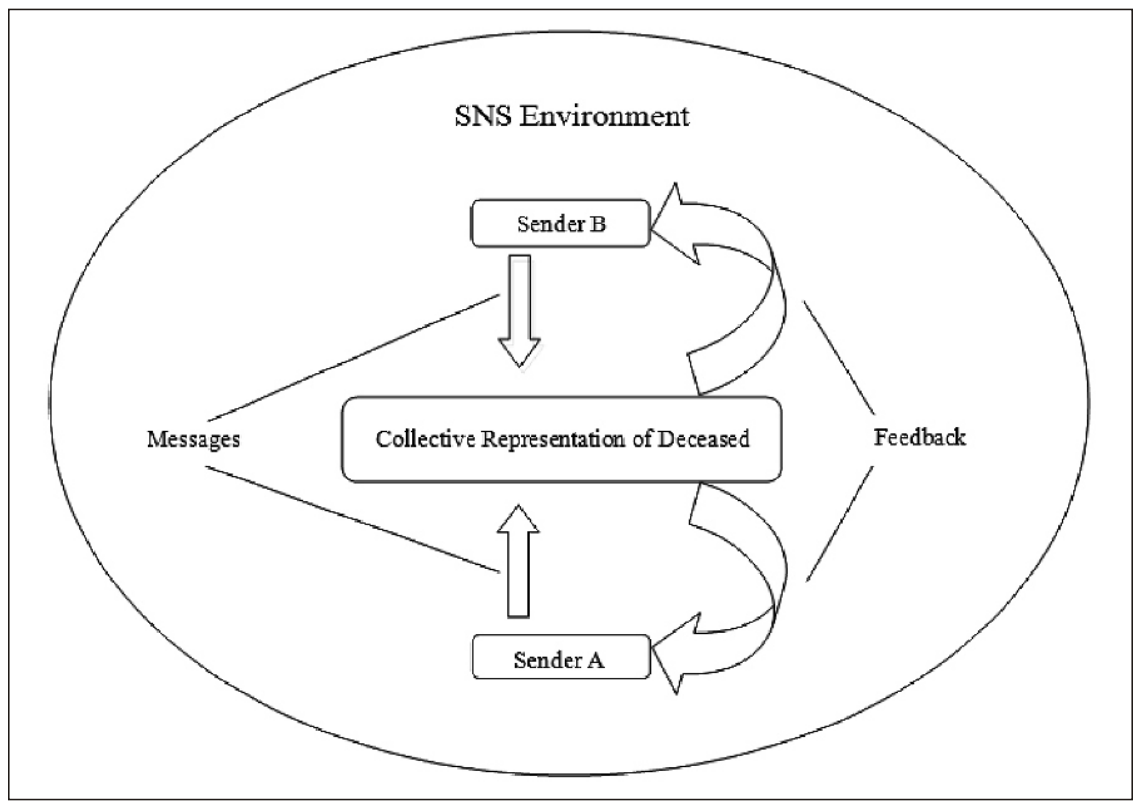

Figure 2. Modified model of TcC for online environments. Note: The collective representation of the deceased is capable of responses outside of the individual message creator in the revised model.

If online grieving acts in part as a time and emotion saving aid, then we see that online grief is not the genesis of new grieving behaviors, but rather the evolution of pre-existing behaviors to accommodate new technologies and facilitate easier interactions while meeting social expectations. This is manifest in regression analysis which stated that, in large part, coping strategies and overall acceptability of online grieving is heavily predicted by personal motivations, perceptions of the motivations of others, and personal religiosity. People are able to meet external obligatory forces both from their peers (normalcy of others) and their spiritual leaders (personal religiosity) while still fulfilling personal needs and motivations via these online opportunities. Individuals can economically satisfy their sense of yearning, which can often be a negative behavior. However, by lowering the cost of the behavior via SNS utilization, individuals can take a behavior that was problematic and move toward acceptance in a group environment that is positive but still allows individuals to pass through the stages of grief at their own pace.

SNS also archive messages indefinitely. These archival representations offer long-term support for people who experience loss and have lapses in the healing process. Also, even though there was not support for close ties grieving online, so we did not investigate the extent to which close ties passively consume SNS 
content on behalf of the deceased. A bereaved mother, friend, or partner may turn to these digital repositories of the dead for some form of catharsis - even if they are not actively participating in the online discussion.

This work is limited by its sample, and investigations into more mature populations who have greater levels of death experience need exploration. Future research needs to continue building on the investigation of online grief by beginning textual analyses of messages to determine status in the grief cycle, and to help build a model to identify struggling grievers who are not adjusting to the loss of an individual in a healthy way. Furthermore, the pervasive nature of online grief needs to be explored in other demographics that are less likely to have death under tragic circumstances. Young adults who have persons die in their SNS often lose those individuals to particularly difficult and sudden circumstances like war, car crashes, overdoses, and accidents. Investigations into groups with terminal illnesses, or aging populations is worthy of investigation to see the extent to which these findings are generalizable across populations.

It is worthwhile to note that personal religious activity and gender differences drive the perceptions of normalcy from the self, as well as perceptions of normalcy from others in regard to online grieving. These two variables then predict likelihood of someone participating in online grieving behaviors. The ramification for this information at a minimum means that self-identity and its maintenance in large part drives what is acceptable during times of loss. Bereaved individuals turn not only inward, but to their groups for a sense of identity and appropriate behavior. If individuals store a piece of themselves in their network, then it stands to reason that the loss of somebody in that network means a loss of a small piece of the self, and having a digital archive of those exchanges, and an active online SNS community may be an efficient and healthy way of regaining that lost piece of the self.

\section{REFERENCES}

Akert, R. M., Aronson, E., \& Wilson, T. D. (2007). Social psychology. Upper Saddle River, NJ: Prentice Hall.

Aloise-Young, P.A., Graham, J. W., \& Hansen, W. B. (1994). Peer influence on smoking initiation during early adolescence: A comparison of group members and group outsiders. Journal of Applied Psychology, 79, 281-287. doi: 10.1037/0021-9010.79.2.281

Arthur, P. (2009). Trauma online: Public exposure of personal grief and suffering. Traumatology, 15, 65-75. doi: 10.1177/1534765609350781

Bosticco, C., \& Thompson, T. (2005). The role of communication and storytelling in the family grieving system. The Journal of Family Communication, 5(4), 255-278.

Brubaker, J. R., \& Hayes, G. R. (2011). "We will never forget you [online] ”: An empirical investigation of post-mortem MySpace comments. Proc CSCW 2011. Hangzhou, China. March 19-23, 2011.

Choi, J. H. (2006). Living in cyworld: Contextualising cy-ties in South Korea. In A. Bruns \& J. Jacobs (Eds.), Use of blogs (Digital formations) (pp. 173-186). New York, NY: Peter Lang. 
Christopherson, K. M. (2007). The positive and negative implications of anonymity in Internet social interactions: "On the Internet nobody knows you're a dog." Computers in Human Behavior, 23(6), 3038-3056. doi: 10.1016/j.chb.2006.09.001

Claes, N., Hurley, C. M., \& Stefanone, M. A. (2012). Online. Proceedings of the 45th Annual Hawai ' $i$ International Conference on Systems Science (HICSS-45), pp. 44174426. January 4-7, Maui.

Cohen, S. (2004). Social relationships and health. American Psychologist, 59, 676-684. doi: 10.1037/0003-066x.59.8.676

Collins Tidwell, L., \& Walther, B. (2006). Computer mediated communication effects on disclosure, impressions, and interpersonal evaluations: Getting to know one another a bit at a time. Human Communication Research, 28, 317-348.

DeGroot, J. M. (2009a). Transcorporeal communication and the presence of the deceased other. National Communication Association, 2009. Chicago.

DeGroot, J. M. (2009b). Reconnecting with the dead via Facebook: Examining transcorporeal communication as a way to maintain relationships. An unpublished doctoral dissertation, Ohio University, Athens, $\mathrm{OH}$.

DeGroot, J. M. (2012). Maintaining relational continuity with the deceased on Facebook. Omega: Journal of Death and Dying, 65(3), 195-212.

Detmer, C. M., \& Lamberti, J. W. (1991). Family grief. Death Studies, 15, 363-374. doi: $1080 / 07481189108252441$

Falconer, K., Gibson, K., Norman, H., \& Sachsenweger, M. (2011, April). Grieving in the Internet age. Penn Medicine: Center for Cognitive Therapy. Available at http://works. bepress.com/penn_cct/1

Friedmann, E., Thomas, S. A., Liu, F. Morton, P. G., Chapa, D., \& Gottlieb, S. S. (2006). Relationship of depression, anxiety, and social isolation to chronic heart failure outpatient mortality. American Heart Journal, 5, 1-8. doi: 10.1016/j.ahj.2006.05.009

Gilbertson, J., Dindia, K., \& Allen, M. (1998). Relational continuity constructional units and the maintenance of relationships. Journal of Social and Personal Relationships, 15, 774-790. doi: 10.1177/0265407598156004

Glick, I. O., Weiss, R. S., \& Parkes, C. M. (1974). The first year of bereavement. New York, NY: John Wiley, Interscience.

Granovetter, M. (1973). The strength of weak ties. American Journal of Sociology, 78, 1360-1379.

Granovetter, M. (1982). The strength of weak ties: A network theory revisited. In Social structure and network analysis (pp. 105-130). Sage, CA: Beverly Hills.

Gross, G., Acquisti, A., \& Heinz, H. J. (2005, November). Information revelation and privacy in online social networks. In the Proceedings of the 2005 ACM workshop on Privacy in the electronic society. Alexandria, VA.

Haferkamp, C. J. (1991). Orientations to conflict: Gender, attributions, resolution strategies, and self-monitoring. Current Psychology, 10, 227-240. doi: 10.1007/bf02686895

Hallam, E., Hockey, J., \& Howarth, G. (1999). Beyond the body: Death and social identity. London and New York: Routledge.

Hess, A. (2000). Maintaining nonvoluntary relationships with disliked partners: An investigation into the use of distancing behaviors. Human Communication Research, 26, 458-488. doi: 10.1111/j.1468-2958.2000.tb00765x

House, J. S., Landis, K. R., \& Umberson, D. (1988). Social relationships and health. Science, 29, 540-545. 
Huebner, A. J., \& Howell, L. W. (2003). Examining the relationship between adolescent sexual risk-taking and perceptions of monitoring, communication, and parenting styles. The Journal of Adolescent Health, 1, 71-78. doi: 10.1016/S1054-139X(03) 00141-1

Ibarra, H. (1992). Homophily and differential returns: Sex differences in network structure and access in an advertising firm. Administrative Science Quarterly, 37, 422-447.

Johnson, A. J., Haigh, M. M., Becker, J. A. H., Craig, E. A., \& Wigley, S. (2008). College students' use of relational management strategies in email in long-distance and geographically close relationships. Journal of Computer-Mediated Communication, 13, 381-404. doi: 10.1111/j.1083-6101.2008.00401.x

Klass, D., Silverman, P. R., \& Nickman, S. (1996). Continuing bonds: New understandings of grief. New York, NY: Taylor \& Francis.

Koenig, H. G., Meador, K., \& Parkerson, G. (1997). Religion index for psychiatric research: A 5-item measure for use in health outcome studies. American Journal of Psychiatry, 154, 885-886.

Laursen, B., \& Bukowski, W. M. (1997). A developmental guide to the organization of close relationships. International Journal of Behavioral Development, 21, 747-770. doi: $10.1070 / 016502597384659$

Lester, D. (2012). Bereavement after suicide: A study of memorials on the internet. Omega: Journal of Death and Dying, 65, 189-194. doi: 10.2190/om.65.3.b

Maciejewski, P. K., Zhang, B., Block, S. D., \& Prigerson, H. G. (2007). An empirical examination of the stage theory of grief. Journal of the American Medical Association, 297, 716-723. doi: 10.1001/jama.297.7.716

Maguire, K. C., \& Kinney, T. A., (2010). When distance is problematic: Communication, coping, and relational satisfaction in female college students' long-distance dating relationships. Journal of Applied Communication Research, 38, 27-46. doi: 10.1080/ 00909880903483573

Marsden, P. V., \& Campbell, K. E., (1984). Measuring tie strength. Social Forces, 63, 482-501.

McCarty, E. F. (1996). Caring for a parent with Alzheimer's disease: Process of daughter caregiver stress. Journal of Advanced Nursing, 23, 792-803.

McPherson, M., Smith-Lovin, L., \& Cook, J. M. (2001). Birds of a feather: Homophily in social networks. Annual Review of Sociology, 27, 415-444.

Mitchell, M. (2007). Constructing immortality: The role of the dead in everyday life. In M. Mitchell (Ed.), Remember me (pp. 1-18). New York, NY: Routledge.

Nager, E. A., \& DeVries, B. (2004). Memorializing on the world wide web: Patterns of grief and attachment in adult daughters of deceased mothers. Omega: Journal of Death and Dying, 49, 43-56.

Rosen, D., Stefanone, M. A., \& Lackaff, D. (2010, January). Online and offline social networks: Investigating culturally-specific behavior and satisfaction. In the Proceedings of the 43rd Annual Hawaii International Conference on Systems Science (HICSS). Los Alamitos, CA: IEEE Press.

Rui, J., \& Stefanone, M. A. (2013). Strategic self-presentation online: A cross-cultural study. Computers in Human Behavior, 29(1), 110-118. doi: 10.1016/j.chb.2012. 07.022

Sanderson, J., \& Cheong, P. H. (2010) Tweeting prayers and communicating grief over Michael Jackson online. Bulletin of Science, Technology and Society, 30(5), 328-340. 
Sigman, S. J. (1991). Handling the discontinuous aspects of continuous social relationships: Toward research on the persistence of social forms. Communication Theory, 2, 106127. doi: 10.1111/j.1468-2885.1991.tb00008.x

Stefanone, M. A., \& Jang, C. Y. (2007). Writing for friends and family: The interpersonal nature of blogs. Journal of Computer-Mediated Communication, 13(1), 123-140.

Stefanone, M. A., Kwon, K. H., \& Lackaff, D. (2012). Exploring the relationship between perceptions of social capital and enacted support online. Journal of Computer Mediated Communication, 17, 451-466. doi:10.1111/j.1083-6101.2012.01585.x

Stroebe, M., \& Schut, H. (1999). The dual process model of coping with bereavement: rationale and description. Death Studies, 23, 197-224.

Stromer-Galley, J., \& Martey, R. M. (2009). Visual spaces, norm governed places: The influence of spatial context online. New Media and Society, 11, 1041-160. doi: $10.1177 / 1461444809336555$

Tajfel, H., \& Turner, J. C. (1986). The social identity theory of intergroup behaviour. Psychology of intergroup relations (pp. 7-24). Chicago, IL: Nelson-Hall.

Tu, C., Yen, C., \& Blocher, M. (2011). A Study of the relationship between gender and online social presence. International Journal of Online Pedagogy and Course Design (IJOPCD), 1(3), 33-49. doi:10.4018/ijopcd.2011070103

Walther, J. B. (2002). Interpersonal effects in computer-mediated interaction: A relational perspective. Communication Research, 19, 52-90. doi: 10.1177/009365092019001003

Walther, J. B. (2007). Selective self-presentation in computer-mediated communication: Hyperpersonal dimensions of technology, language, and cognition. In Computers in Human Behavior, 23, 2538-2557. doi:10.1016/j.chb.2006.05.002

Walther, J. B. (2012). Interaction through technological lenses: Computer-mediated communication and language. Journal of Language and Social Psychology, 31(4), 397-414. doi: 10.1177/0261927x12446610

Walther, J. B., \& Boyd, S. (2002). Attraction to computer-mediated social support. In Communication technology and society: Audience adoption and uses (pp. 153-188). Cresskill, NJ: Hampton Press.

Walther, J. B., Van Der Heide, B., Kim, S. Y., Westerman, D., \& Tong, S. Y. (2008). The role of friends' appearance and behavior on evaluations of individuals on Facebook: Are we known by the company we keep? Human Communication Research, 34(1), 28-49.

Wesselmann, E. D., \& Williams, K. D. (2010). The potential balm of religion and spirituality for recovering from ostracism. Journal of Management, Spirituality, and Religion, 7(1), 31-49. doi: 10.1080/14766080903497623

Direct reprint requests to:

Michael J. Egnoto

Department of Communication

University at Buffalo

Buffalo, NY 14260

e-mail: michaelegnoto@gmail.com 